
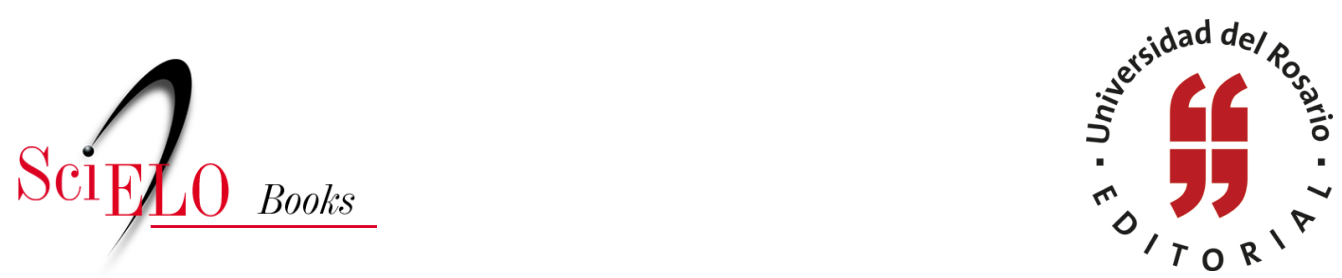

\title{
Monumentos como alegorías de la nación entre el Imperio y la Primera República de Brasil
}

\author{
Georg Wink
}

\section{SciELO Books / SciELO Livros / SciELO Libros}

WINK, G. Monumentos como alegorías de la nación entre el Imperio y la Primera República de Brasil. In: SCHUSTER, S., ed. La nación expuesta. Cultura visual y procesos de formación de la nación en América Latina [online]. Bogotá: Editorial Universidad del Rosario, 2014, pp. 101-121. Textos de ciencias humanas collection. ISBN: 978-958-738-524-3. https://doi.org/10.7476/9789587385243.0007.

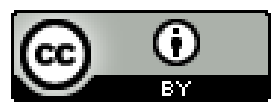

All the contents of this work, except where otherwise noted, is licensed under a Creative Commons Attribution 4.0 International license.

Todo o conteúdo deste trabalho, exceto quando houver ressalva, é publicado sob a licença Creative Commons Atribição 4.0.

Todo el contenido de esta obra, excepto donde se indique lo contrario, está bajo licencia de la licencia Creative Commons Reconocimento 4.0. 


\section{Monumentos como alegorías de la nación entre el Imperio y la Primera República de Brasil}

Georg Wink

Københavns Universitet

En los estudios sobre la formación de la nación, se considera el fin del siglo XIX como el auge de difusión de representaciones alegóricas nacionales. Entre ellas cumplen un papel destacado los monumentos cívicos que didácticamente "narran" la nación. Para eso dependen de códigos de interpretación que no son evidentes, sino construidos por medio de discursos que acompañan la génesis de los monumentos y los festejos organizados en torno a ellos. En el caso del Brasil, llama la atención que la producción de monumentos es tardía y casi vacilante en comparación con Hispanoamérica. Los pocos monumentos inaugurados en esta época difícilmente fueron aceptados bajo consenso y el pretendido efecto didáctico fue a la vez invertido por la falta de coherencia en los discursos nacionalistas. En este capítulo se muestran algunos ejemplos de cómo las narrativas oficiales son desbaratadas: sea por la competencia entre los diferentes símbolos nacionales de las élites, por las voces disonantes de los subalternos o por el fracaso de la puesta en escena frente a la realidad social. Se atribuye ese fenómeno, dentro del contexto histórico específico de Brasil (independencia como Imperio, República “involuntaria”), no a la expresión menor de un espíritu nacionalista, sino a la existencia de una tradición ya establecida de una imagen de Brasil que, por su capacidad de inclusión simbólica, hasta cierto punto inutiliza o dispensa de las nuevas representaciones nacionales.

Cuando se trata de monumentos nacionales, se avanza necesariamente en un área de interés interdisciplinar entre historia, historia del arte, arquitectura, estudios culturales y literarios. Eso porque ya no se pueden tratar los monumentos puramente 
como objetos históricos "dados" que informan sobre su contexto. Tampoco basta considerarlos objetos apenas estéticos y hacer un análisis iconográfico. Además, la relación entre forma y contenido es, en muchos casos, arbitraria. Y, sobre todo, el sentido atribuido a un monumento es dinámico y varía conforme los tiempos y las ideas hegemónicas, o sea: se puede utilizar el mismo molde de una estatua ecuestre para personajes y épocas diferentes (y de hecho se hacía). Quiere decir que la expresión formal-estilística de un monumento "nacionalista" no expresa necesariamente el carácter del "nacionalismo" en una determinada época y sociedad (Rausch 2006, 66). Eso no significa que la estética formal sea toda irrelevante, sino que es insuficiente para definir la nación y su mensaje programático.

Con estas breves consideraciones introductorias y relativizaciones teóricas se busca mostrar, resumidamente, que los monumentos al principio son vacíos - a no ser por su ubicación en el tiempo histórico y en el espacio social- Consecuentemente, necesitan una interpretación para cumplir su función frente a los espectadores. Esa interpretación se da a través de textos, a veces inscritos en el propio monumento, pero sobre todo en textos paralelos, folletines y artículos de periódico, y, todavía más, orales en las fiestas de inauguración y homenaje alrededor de los monumentos. Esos textos acostumbran recurrir a estructuras narrativas semejantes a las ficcionales.

Por ende, en este capítulo se estudian los monumentos principalmente como paneles de proyección de un complejo de enunciaciones. Básicamente, se enfoca en los discursos que explican los monumentos, es decir, se aborda tanto lo representado como su lenguaje de representación. Es posible hablar de un lenguaje del monumento, porque son signos visuales monumentales que recurren a medios de representación retóricos y didácticos. En muchos casos esos discursos acompañan la génesis del monumento y se fortalecen en las solemnes festividades de inauguración. La génesis acostumbra ser un proceso largo: primero la fundación de un comité y la recaudación de fondos, después la competición de modelos, la presentación a las autoridades, la selección del modelo y del artista, finalmente la selección del lugar de erección (Tacke 1995, 28). Todo el proceso acostumbra encontrar su eco en los periódicos. Como ya he mencionado, en ocasiones los discursos también están inscritos en el propio monumento, por ejemplo, en motes o impresos en textos "manuales".

Este abordaje tiene, por lo menos, dos implicaciones problemáticas que necesitan ser aclaradas antes. Primero, significa que debieran incluirse en el análisis los monumentos que fueron proyectados y discutidos en su tiempo, pero nunca 
realizados. Es claro que esto exige mucha investigación, porque no podemos hacer una simple relación de los monumentos que existen en las calles y plazas. Para este estudio no pudo realizarse tal trabajo, lo cual es lamentable, pues los monumentos nunca realizados pueden ser los más interesantes al haber sido los más radicales y, por ende, controversiales. Se quedan afuera del consenso y la discusión sobre ellos es reveladora. La segunda implicación es que la oposición, por regla, no logra proyectar ni construir monumentos. Es un privilegio del propio Estado o de grupos aliados que apoyan al Estado. O sea, se trata de una cuestión de la hegemonía de poder y de opinión, estando la heterogeneidad histórica parcialmente excluida, en su parte menos o nada privilegiada.

Para esas implicaciones hay una posible salida, dada justamente por el cuidado requerido al examinar el contexto discursivo; si no se incluyeron en el análisis los monumentos rechazados o los contramonumentos que fueron al menos imaginados, las voces disonantes sí están presentes a través de sus comentarios críticos a los monumentos oficiales, a veces con actitudes casi iconoclastas. De esas críticas hubo un gran número, sobre todo en los periódicos que mostraron, en el caso de Brasil, una recepción bastante crítica de los monumentos nacionales, así como de todos los fenómenos del discurso nacional simbólico: criticaban la memoria ecléctica y selectiva, el constructivismo manipulador y la dicotomía entre vencedores/ vencidos o buenos/malos. Hubo casos incluso en los que la sátira periodística -o la involuntaria sátira cotidiana - prácticamente inutilizó un monumento una vez que lo inauguraron. Debe mencionarse también que la hegemonía de opinión, por lo menos en el caso de los monumentos brasileños estudiados, no es nada homogénea. Acerca de todos los monumentos existe una variedad dentro del discurso hegemónico, hay opiniones controvertidas: de los militares, de los jacobinos, de los florianistas, de los positivistas, de la Iglesia. Eso muestra que nunca hubo, por parte de las élites, una hegemonía de símbolo sin límites, pero sí una competición de símbolos, y nunca hubo un monopolio de su interpretación.

Es necesario añadir, asimismo, que como "monumentos nacionales" se comprenden aquí los monumentos con intención nacional, o sea, que en sus contemporáneos despertaron claramente un sentido "nacional". Ese efecto puede derivar de varias características en combinación: que es la "Nación” que hizo la donación del monumento, que este está dirigido en homenaje a la "nación”, que el monumento representa alegóricamente algo relevante para el discurso nacional. En el último caso, que evidentemente es el más frecuente, la representación puede referirse a personas como gobernadores (por ejemplo D. Pedro I o Napoleón I), héroes (Simón 
Bolívar o el almirante Nelson, en el topo de la famosa columna del Trafalgar Square), genios (como Benjamin Constant o Voltaire), supuestos antepasados (como Cuauhtémoc, Arminio el Cerusco o Cabral), acontecimientos como batallas (las batallas de la Guerra de la Triple Alianza), ideas y símbolos significativos para la nación (el indio que suelta las cadenas, el sol incaico, la india republicana de gorro frígido). En toda representación, el efecto deseado es que el monumento radique en el pasado y eternice para el futuro la nación y que el monumento sea aceptado fácilmente como un símbolo permanente de una identidad nacional. Es, en las palabras de Hugo Achugar, "la objetivación de la memoria" $(1998,47)$.

Seguidamente, me detendré en los monumentos nacionales en la capital del imperio y de la república de Brasil, Río de Janeiro. La hipótesis general, que tiene su origen en mis estudios sobre la construcción discursiva del Brasil (véase Wink 2009) y que guía mi análisis, es que el caso específico brasileño representa una excepción entre los países latinoamericanos por su formación histórica diferente: la colonización portuguesa, la fusión de metrópoli y colonia en un Reino Unido, el traslado de la corte, la independencia como imperio, la manutención de la integralidad del territorio y la república tardía. Por esas peculiaridades, la producción de símbolos nacionales fue de cierta manera dificultada o hasta temporalmente dispensada por la presencia de una tradición discursiva de continuidad y de conciliación que transporta la idea de un Brasil imaginado, pero de alguna manera definido, que es el Brasil isla, paraíso, Quinto Imperio o País del Futuro; el Brasil no republicano, pacífico, etc. O sea, por ya existir una idea potente y de cierta manera afirmada de Brasil, el trabajo representativo y memorialístico de la nación tuvo, en la época estudiada y en términos relativos a América Latina, menos fuerza y menos repercusión.

¿Desde cuándo existen monumentos "nacionales" en el mundo y en Brasil? Esta pregunta depende del concepto nación. El modelo patrón de estatuas ecuestres, por ejemplo, tiene una historia de dos milenios. La famosa estatua del emperador Marco Aurelio del siglo II posiblemente se ubique al comienzo de la tradición del monumento monárquico, personalizado, que se prolongó por las estatuas de las ciudades-repúblicas italianas medievales y las estatuas ecuestres reales hasta el culto personal a Napoleón I. $^{1}$ Pero para la mayoría de los estudiosos que se ocupan de la formación de la nación, está bastante claro que la idea de nación es mucho más reciente, asociada como idea a la filosofía de las luces, vinculada estructuralmente

1 Sigo, en este trecho, la tipología del monumento nacional desarrollada por Nipperdey (1976, 133-173). 
a los procesos de transformación económica y social de la modernidad como época industrial, y políticamente a su realización estatal en la independencia de las trece colonias y en la Revolución Francesa.

De hecho, en Francia, durante la segunda mitad del siglo XVIII surge, como novedad, el monumento al grand homme civil, dedicado al filósofo, al legislador, al magistrado, al orador, al negociante y al guerrero. No resulta sorprendente que, durante la Revolución Francesa, la iglesia de St. Geneviève fuera transformada en Panteón en 1791 (Ozouf 1984, 144). Este tipo de monumento, ya no dinástico, se podría llamar monumento histórico-cultural, en muchos casos con una interesante función compensatoria (la conquista en el campo de la literatura y la lengua, por la falta de libertad y participación política). Para el contexto europeo podemos verificar una nueva presencia de monumentos nacional-democráticos como alegorías de la nación, pero apenas desde los años 1830. Son paradigmáticas las columnas y los obeliscos constitucionales. Pero, vale decir, prevalece en Europa el tradicional monumento monárquico, y no son muchos. ${ }^{2}$ Francia apenas entra en la famosa fase de "estatuomanía" en la Tercera República, o sea, en 1870-1871 (Agulhon 1988). El fenómeno en el cual los monumentos se transforman en lugar preferido de fiestas cívicas y otras prácticas rituales también data de los años 1870, el inicio de la época en la cual, según Hobsbawm, "it increasingly did matter how ordinary common men and women felt about nationality" (1990, 38). Sin embargo, la participación de pequeños burgueses y operarios continuó siendo marginal hasta la primera guerra mundial. Todavía no se aprovechaban las fiestas para propagar otros mecanismos del nacionalismo, como entonar himnos nacionales o declarar feriados nacionales.

En Brasil, es considerado el primer monumento "nacional" la famosa estatua ecuestre de D. Pedro I, inaugurada en 1862 (antes fue realizada una columna en memoria de la llegada de la emperatriz Teresa Cristina, en 1843, pero hoy se ha olvidado). Durante el Imperio, a Pedro I le siguió (en pie) José Bonifacio, el patriarca de la independencia, en 1872. Otros monumentos nacionales fueron realizados en la capital apenas después de la proclamación de la República. Si intentamos una comparación con algunas capitales europeas (tabla 1), no queda duda de que, por lo menos, sería una exageración hablar de "estatuomanía brasileña" (Enders $2000,55) .^{3}$

2 Véase la contabilización de monumentos nacionales en tres capitales europeas en Rausch (2006, 699-710).

3 La división de los periodos es oriunda del contexto europeo, pero también de significado para el 
Tabla 1. Monumentos erigidos en capitales de Europa/Brasil (1848-1914)

\begin{tabular}{|l|c|c|}
\hline & $\mathbf{1 8 4 8 - 1 8 7 0 / 1 8 7 1}$ & $\mathbf{1 8 7 0 / 1 8 7 1 - 1 9 1 4}$ \\
\hline París & 10 & 68 \\
\hline Berlín & 9 & 50 \\
\hline Londres & 17 & 44 \\
\hline Río de Janeiro & 3 & 14 \\
\hline
\end{tabular}

Fuentes: Rausch (2006), Fund. Parques e Jardins (http://www.monumentosdorio.com.br).

Aquí sorprenden, es de suponerse, más que los números bajos de Brasil, los números igualmente bajos en Europa, por lo menos hasta 1870/1871. La comparación más interesante, siguiendo la hipótesis de una representación nacionalista vacilante en Brasil, es con las principales capitales de Hispanoamérica (tabla 2).

Tabla 2. Monumentos erigidos en capitales de Latinoamérica (1848-1914)

\begin{tabular}{|l|c|c|}
\hline & $\mathbf{1 8 4 8 - 1 8 7 0 / 1 8 7 1}$ & $\mathbf{1 8 7 0 / 1 8 7 1 - 1 9 1 4}$ \\
\hline Río de Janeiro & 3 & 14 \\
\hline Buenos Aires & 4 & 36 \\
\hline Santiago de Chile & 5 & 4 \\
\hline Lima & 5 & 10 \\
\hline Caracas & 0 & 15 \\
\hline México & 5 & 4 \\
\hline
\end{tabular}

Fuentes: Gutiérrez Viñuales (2004), Fund. Parques e Jardins (http://www.monumentosdorio.com.br).

A primera vista se percibe que, en general, los números tienden a elevarse, sobre todo en el caso de Buenos Aires, capital de un país indefinido hasta 1861, cuando se estableció el gobierno de Bartolomé Mitre. Además, tenemos que considerar en estas cifras el alto costo de las estatuas que se fundían en talleres de Europa, por lo menos hasta 1890. Incluso, hasta el final del periodo considerado fueron proyectados casi únicamente por artistas europeos, con pocas excepciones (Gutiérrez

contexto brasileño, donde en 1870 se finalizó la guerra de la Triple Alianza, en 1871 se promulgó, como primer paso a la abolición de la esclavitud, la Ley del Vientre Libre y en 1873 se fundó el Partido Republicano Paulista. 
Viñuales 2004, 132 y ss.). ${ }^{4}$ Lo que por estos números no se ve es que los primeros monumentos (muchos de ellos erigidos muy tempranamente, ya en la época de las guerras de la independencia) fueron columnas, obeliscos y pirámides y no los tradicionales monumentos personalizados, al contrario de la preferencia en Europa. Muchas veces fueron rematados con figuras que representaban la libertad, águilas y cóndores. Entre los primeros ejemplos están la bien conocida Pirámide de Mayo, de 1811, en Buenos Aires, y la Libertad Americana, de 1836, en Santiago de Chile, una pila, en homenaje a la libertad americana (figura 1): la figura de pie personifica la libertad, una mujer vestida al modo clásico, como una diosa de la guerra, Atenea o Minerva, con la mano derecha levanta un mazo para romper las cadenas en los pies de la india americana. El medallón de frente es un homenaje a Bolívar (cuando todavía estaba vivo, en la fase de planeamiento en 1827). Los otros tres medallones muestran episodios de la guerra por la independencia: la partida de la escuadra al Perú, la entrada del ejército a Lima y la batalla de Ayacucho. Se trata de un nuevo modelo de presentación muy temprano en las repúblicas jóvenes, fenómeno parecido a la introducción de banderas e himnos en los discursos nacionales latinoamericanos. ${ }^{5}$ La representación abstracta y alegórica obviamente tiene muchas ventajas. Permite la omisión de los agentes de cierta forma no deseados: una representación del Ejército de los Andes, por ejemplo, a través de un grupo de soldados, llevaría a la cuestión, hasta ahora incómoda para la narración nacional, de los numerosos reclutas negros (Blanchard 2008, 86 y ss.). La alegoría por la mitología griega es retóricamente más inclusiva. Por eso las estrategias de omisión y transposición son fundamentales para el lenguaje de los monumentos nacionales.

Comparado con Brasil, el número de monumentos es parecido entre las capitales, pero más bajo cuando se consideran la población, la extensión y el poder político y económico brasileños como hegemónicos dentro de la región latinoamericana de la época. Evidentemente, los cálculos solo permiten una impresión, pero resulta bastante claro que el número es tendencialmente más bajo. Que en Brasil

4 Lo que explica algunos errores iconográficos terribles, por ejemplo, el Atahualpa de Lima, representado como piel roja norteamericano. Hubo sí artistas latinoamericanos competentes, si pensamos en la rica producción de la escultura religiosa barroca en Latinoamérica; pero en el siglo XIX su producción artística entró en descenso. La introducción de la estatuaria conmemorativa, de los nuevos jefes militares o civiles de las repúblicas o de monumentos alegóricos, fue acompañada con un reemplazazo de artistas locales por importados.

5 En un ramo de los estudios sobre la nación, que parte de la hipótesis de la existencia de creolepioneers (Anderson 1991), se examina justamente este fenómeno. 


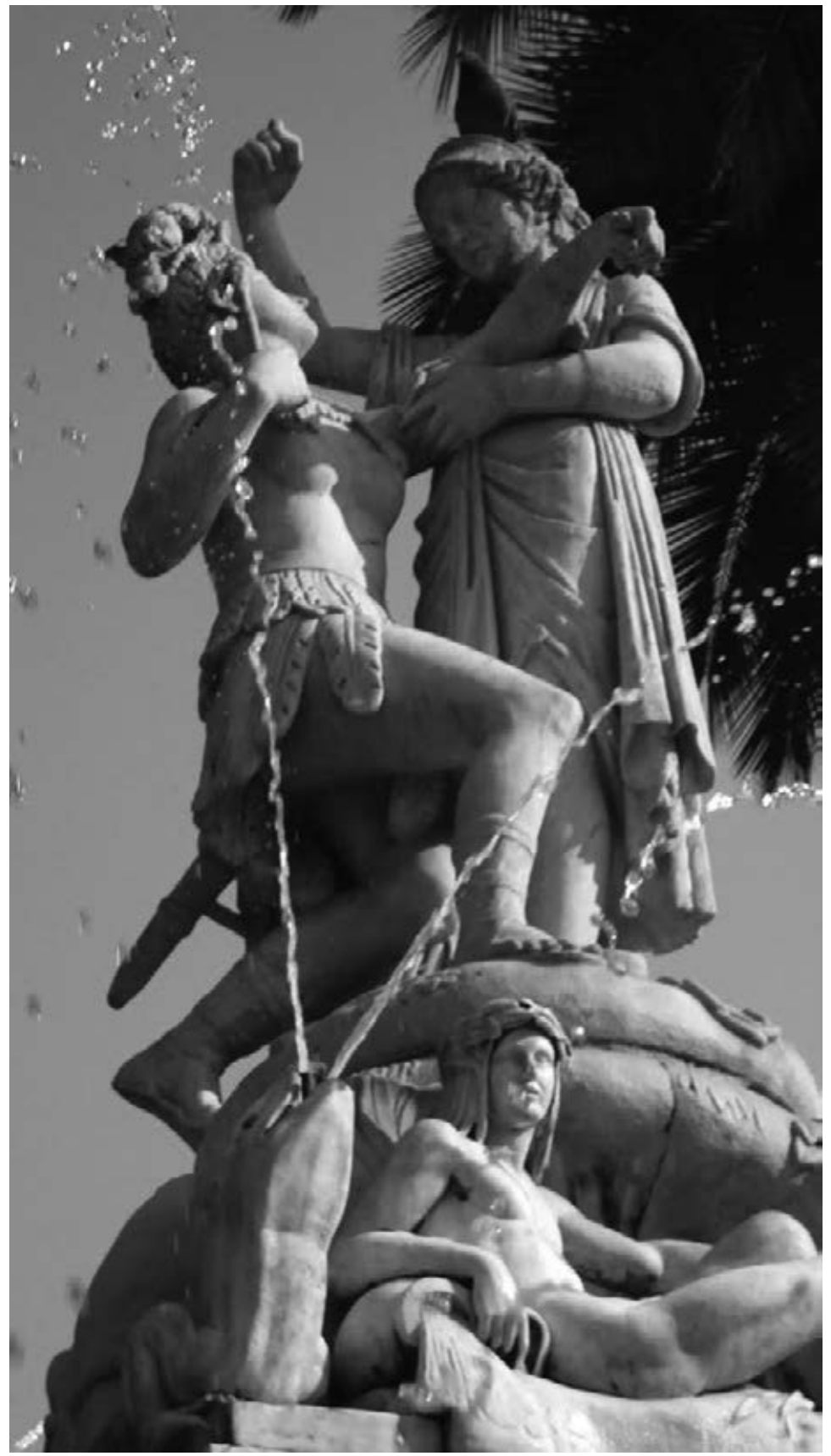

Figura 1. Monumento a la Libertad Americana

Fuente: fotografía de Andrés Ormaechea. 
la pedagogía cívica por intermedio del ejemplo dado en estatuas se estableció más tarde, lo podemos percibir también por las constantes reclamaciones por parte de personas públicas que bien percibieron el poder del símbolo en las repúblicas vecinas, por ejemplo, el historiador Joaquim Norberto de Sousa Silva, que escribe con optimismo en 1862: "O Brasil terá em breve estátuas de seus imperadores, a coluna gigantesca de sua independencia, a cruz colossal do seu descobrimento” (Enders 2000, 55). Pero Brasil, en realidad, solo obtuvo una estatua para D. Pedro I, y, como se mostrará en breve, fue un consenso difícil. En los últimos años del Imperio hubo más proyectos, republicanos o positivistas, pero solamente fueron realizados en la República (tabla 3).

Tabla 3. Lista de monumentos erigidos en Río de Janeiro (1843-1965)

\begin{tabular}{|c|c|c|c|}
\hline 1843 & Obelisco (Llegada D. Teresa Cristina) & 1926 & Guerra Uruguay (Batalla Passo del Rosário) \\
\hline 1862 & D. Pedro I & 1927 & Francisco de Assis \\
\hline 1872 & José Bonifácio (político) & 1929 & Machado de Assis (escritor) \\
\hline 1890 & João Caetano (artista) & 1931 & Monumento de Amistad con Estados Unidos \\
\hline 1894 & Gen. Osório & 1931 & Pinheiro Machado (político) \\
\hline 1897 & José de Alencar (escritor) & 1937 & Pres. Deodoro Fonseca \\
\hline 1899 & Mariscal Duque de Caxias & 1937 & Gob. João Pessoa \\
\hline 1900 & Pedro Álvares Cabral & 1937 & Alm. Marquês de Tamandaré \\
\hline 1902 & Vizc. Rio Branco (diplomata) & 1938 & Represión a la intentona comunista \\
\hline 1905 & Abg. Teixeira de Freitas & 1938 & Guerra Paraguay (Batalla Laguna y Dourados) \\
\hline 1906 & Obelisco (Inauguración Av. Central) & 1938 & D. Pedro II \\
\hline 1908 & Ing. Cristiano Ottoni & 1938 & Eng. Manuel Buarque de Macedo \\
\hline 1909 & Alm. Barroso & 1941 & Vizc. Varnhagen (historiador) \\
\hline 1910 & Pres. Floriano Peixoto & 1942 & Santos Dumont (aviador) \\
\hline 1910 & Vizc. de Mauá (empresario) & 1943 & Renacimiento construcción naval bras. \\
\hline 1913 & Alc. Francisco Pereira Passos & 1944 & Miguel Couto (médico) \\
\hline 1918 & Oswaldo Cruz (médico) & 1946 & Alm. Saldanha Gama \\
\hline 1922 & Cuauhtémoc & 1950 & Oswaldo Diniz Magalhães (prof.) \\
\hline 1923 & Aviadores & 1959 & Carlos Gomes (artista) \\
\hline 1923 & Eça de Queiroz (escritor) & 1960 & Abolicionistas \\
\hline
\end{tabular}




\begin{tabular}{|l|l|c|l|}
\hline 1925 & Benjamin Constant (prof.) & 1960 & Muertos de la Segunda Guerra Mundial \\
\hline 1925 & Cristo Redentor & 1961 & Pres. Juscelino Kubitschek \\
\hline 1925 & Louis Pasteur & 1965 & D. João VI \\
\hline 1926 & Tiradentes & 1965 & San Sebastián (patrón de R. Janeiro) \\
\hline 1926 & Barón de Taunay (artista) & & \\
\hline
\end{tabular}

Fuente: Fund. Parques e Jardins (http://www.monumentosdorio.com.br).

La lista revela algunos incrementos en la coyuntura del desarrollo al monumento nacional, por ejemplo, en torno al cuarto centenario del descubrimiento, en los años que siguen al centenario de la independencia y, ya más tarde, en el auge del Estado Novo. La coyuntura gana en significación si se discriminan los números por áreas temáticas, lo que hace posible verificar ciertas preferencias en relación con los contextos históricos (tabla 4).

Tabla 4. Tipología de los monumentos erigidos en Río de Janeiro (1843-1965)

\begin{tabular}{|c|c|c|c|c|c|c|c|c|c|c|c|c|}
\hline & & & & & & & & s & & & & \\
\hline & & & & & & & & 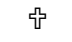 & & & & \\
\hline & & & & & & & & ঋ & (2) & & & \\
\hline & & & & & & & & 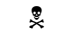 & 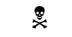 & & & \\
\hline & & & & & & & & $\infty$ & 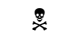 & & & \\
\hline & & & & & & 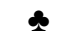 & & 8 & 0 & & & \\
\hline & & & & & & 0 & & $\infty$ & Po & (2) & & ঋ \\
\hline & & & & & $\theta$ & 0 & 0 & 0 & 림 & 8 & & 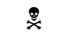 \\
\hline & & & & & 8 & be & 0 & 0 & $\S$ & 0 & & $\sigma^{*}$ \\
\hline & & & & & 的 & $\S$ & 0 & $\sigma^{*}$ & $\S$ & 0 & 8 & 삠 \\
\hline (ㄷ) & & 림 & $\S$ & & 的 & $\S$ & $\S$ & $\S$ & $\S$ & per & 0 & $\S$ \\
\hline $\begin{array}{c}1840- \\
1849\end{array}$ & $\begin{array}{l}1850- \\
1859\end{array}$ & $\begin{array}{l}1860- \\
1869\end{array}$ & $\begin{array}{l}1870- \\
1879\end{array}$ & $\begin{array}{c}1880- \\
1889\end{array}$ & $\begin{array}{c}1890- \\
1899\end{array}$ & $\begin{array}{l}1900- \\
1909\end{array}$ & $\begin{array}{c}1910- \\
1919\end{array}$ & $\begin{array}{c}1920- \\
1929\end{array}$ & $\begin{array}{l}1930- \\
1939\end{array}$ & $\begin{array}{c}1940- \\
1949\end{array}$ & $\begin{array}{c}1950- \\
1959\end{array}$ & $\begin{array}{c}1960- \\
1965\end{array}$ \\
\hline
\end{tabular}

Leyenda:

\begin{tabular}{|c|c|c|c|c|c|}
\hline $\begin{array}{l}\text { 'El orden' } \\
\$ \text { estadista } \\
\text { Pu militar } \\
\text { 'enemigo,' 'mártir' }\end{array}$ & $\begin{array}{l}\text { 'El progreso' } \\
\text { o técnico, } \\
\text { 'civilizador' }\end{array}$ & $\begin{array}{l}\text { 'Arte/Ciencia' } \\
\text { artista, } \\
\text { científico }\end{array}$ & $\begin{array}{l}\text { 'Momentos' } \\
\text { (๖) político- } \\
\text { económico } \\
\& \text { bélico }\end{array}$ & $\begin{array}{l}\text { 'Gracia divina' } \\
\text { ↔ santo }\end{array}$ & $\begin{array}{l}\text { 'Ancestrales' } \\
\text { \$ autóctono, } \\
\text { 'descubridor' }\end{array}$ \\
\hline
\end{tabular}

Fuente: Fund. Parques e Jardins (http://www.monumentosdorio.com.br). 
Del corpus aquí presentado, analizaré, enseguida, tres ejemplos a través de su contexto discursivo: los monumentos a D. Pedro I, Floriano Peixoto y Pedro Álvares Cabral. El primer monumento analizado es la estatua ecuestre de Pedro I, creada por el francés Louis Rochet e inaugurada en 1862 en una plaza central que, en la época, se llamaba Plaza de la Constitución (figura 2).

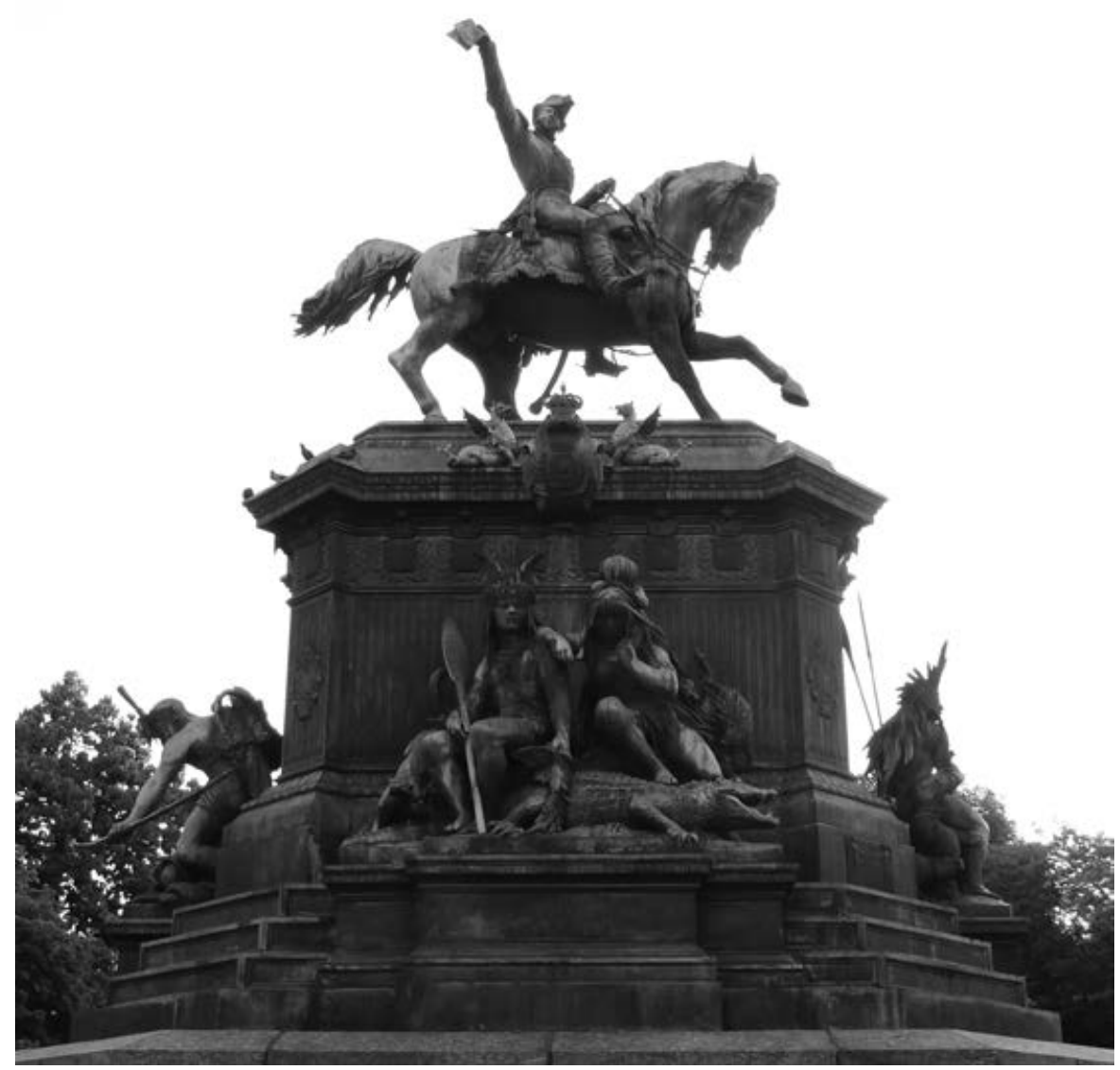

Figura 2. Estátua equestre de dom Pedro I

Fuente: fotografía de Sven Schuster.

Es la primera estatua y tal vez la más polémica. Debido al gran número de estudios sobre el caso, donde destacan el de José Murilo de Carvalho (1990) y el de Stanislav Herstal (1972) —un meticuloso estudio iconográfico-, es bastante fácil comprender el contexto discursivo. La idea inicial, propuesta repetidas veces desde 1824, era la de representar a Pedro I en el momento del grito del Ipiranga, según la 
narración oficial, emitido el 7 de septiembre de 1822, junto a los ciudadanos que contribuirían a alcanzar la independencia (Enders 2000, 56 y ss.). Se podría decir, resumidamente, que quisieron hacer de Pedro I un Bolívar brasileño. Pero en el modelo escogido, la contribución cívica es sustituida por figuras indígenas y animales que representan los ríos Amazonas, Paraná, San Francisco y Madeira. O sea: es la conmemoración del rey y de la naturaleza brasileña, incluida en esta al indio.

La crítica principal vino por parte de los liberales, encabezados por el minero Teófilo Otoni, pues la estatua de Pedro I es erigida justamente en el puesto donde fue ahorcado y descuartizado el inconfidente Tiradentes, en 1793, por mando de la abuela de Pedro, María I (Carvalho 1990, 60 y ss.). Son dos discursos de independencia que entran en choque y que revelan emblemáticamente un dilema: por una parte, el separatismo regional y con tendencia republicana de los inconfidentes, dirigido contra la administración colonial de la corona, y, por otra, el separatismo centralista monárquico-brasileño en consentimiento con la casa real en Portugal, dirigido estratégicamente contra los separatismos republicanos y las cortes de ambos lados del océano. El primero es un discurso apenas existente en la oralidad y en algunas obras literarias (poesías), pero ignorado por el discurso pedagógico. El segundo es un discurso cauteloso, sin hacer de la independencia un elemento central, debido a las delicadas circunstancias históricas (el tratado de paz y amistad con Portugal, el coronamiento de un emperador, la feroz represión contra las cortes republicanas en Brasil con la ayuda de mercenarios), entonces bastante diferentes del modelo de independencia de las repúblicas vecinas. Hay que mencionar que algunos, menos politizados, criticaron también la pose del caballo, que parece que anda a paso de camello, levantando las dos patas izquierdas a la vez. En el día de la inauguración — con orquestra, tedeum, arco de triunfo, fuegos artificialescircularon folletos ridiculizando la solemnidad: "Nos dias da cobardia / Festeja-se a tirania / Fazem-se estátuas aos reis". Y terminan elogiando a Tiradentes: "Foi ele o mártir primeiro / Quepelapátria morreu" (Carvalho 1990, 61). Pero la conclusión más interesante del folleto es que Tiradentes no precisaba de una estatua, porque todos recuerdan su imagen, de pie sobre la horca, con su aureola de libertad y fe (una imagen de Cristo construida por toda una tradición de pinturas), sin necesitar de una presentación en monumento. Las protestas también fueron vehiculadas en la prensa: Machado de Assis critica en el Diario do Rio de Janeiro (1 de abril de 1862):

Já é de mau agouro, se à ereção de um monumento que se diz derivar dos desejos unânimes do pais precedeu uma discussão renhida, acompanhada de adesóes e 
aplausos. O bistoriador futuro que quiser tirar dos debates da imprensa os elementos do seu estudo da história do império, há de vacilar sobre a expressão da memória que hoje domina a praça do Rocio. (Machado de Assis 2008, 197)

De estos problemas de parto, la estatua, llamada "mentira de bronce" (D’Alessandro 2003, 325), nunca se recuperó. Se transformó más bien en referencia para las críticas al gobierno, como en las caricaturas de Angelo Agostini. Los republicanos intentaron varias veces cubrir el monumento en feriados nacionales y lucharon por una estatua de Tiradentes para hacer frente al emperador. Ella se realizó apenas en 1926, pero prudentemente distante un kilómetro, frente al nuevo Palacio Tiradentes, entonces sede del Congreso Nacional. Sin embargo, ya en 1890, con la proclamación de la república, la Plaza dominada por la estatua de D. Pedro I cambió su nombre a Plaza Tiradentes. Es un ejemplo paradigmático para la famosa política brasileña de la conciliación que, también, en el nuevo sistema republicano logró mantener paralelamente los principales símbolos monárquicos.

El segundo monumento es un homenaje a Floriano Peixoto, militar, primero vicepresidente y luego presidente de la República (o dictador, pues se rehusó a entregar el gobierno a los civiles), fallecido en 1895. El brasileño Eduardo de Sá - para el concurso el artista tenía que ser brasileño - proyectó el monumento en 1901 y fue realizado en 1910 en la plaza Cinelândia. La idea surgió como homenaje al militar, en ocasión de los cinco años de su muerte, y fue defendida por el club militar que ya practicaba romerías a la tumba del mariscal (Leal 2004: 5). Es un monumento complejo, con la presencia de un total de 25 personas, que lo deja con aspecto sobrecargado (figura 3). Por eso el pueblo inventó que Floriano, desde lo alto, estaría gritando, con la espada en la mano: “Aqui não sobe mais ninguem!”. La frase caló y fue reproducida con bastante ironía por los periódicos:

Tantos, porém, são os vultos patrióticos enchendo saliências e vãos da solene escultura, que achou o povo de explicar a atitude marcial do Marechal de Ferro, com a sua espada na mão, como a de um homem apavorado com a pletora de tantos companheiros a cerca-lo que, do alto do pedestal em que se encontra, diz, para baixo, entre apreensivo efurioso: Aquinão sobe mais ninguém! (Gazeta de Noticias, Río de Janeiro, 22 de abril de 1910, citado en Leal 2004, 10) 


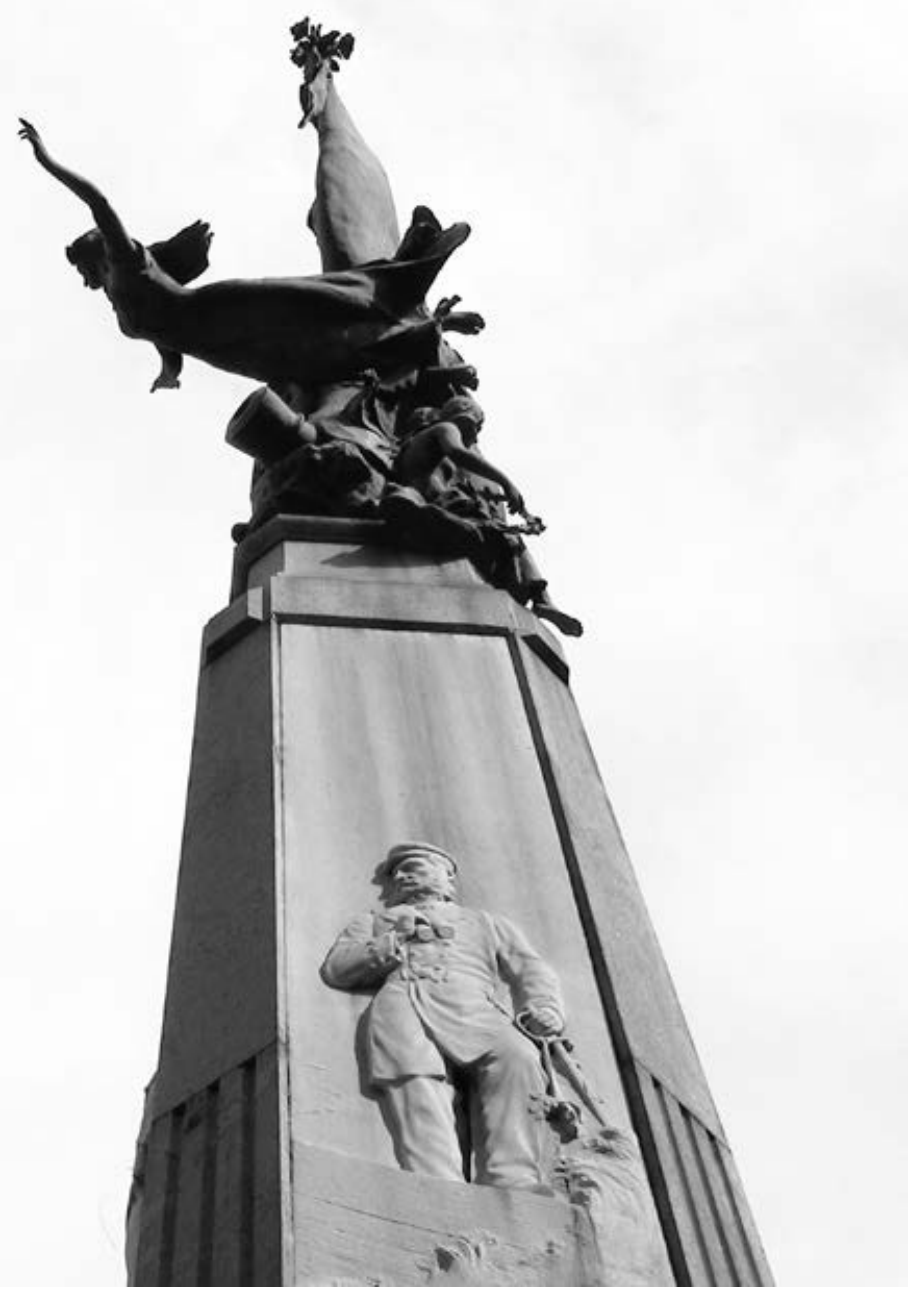

Figura 3. Floriano Peixoto

Fuente: fotografía de Daniela Verztman.

En el alto de la columna vemos a Floriano que defiende la bandera desplegada, esa con bajorrelieves de Tiradentes, José Bonifácio y un busto de Benjamin Constant. Una alegoría femenina, flotando encima del mariscal, bendice el pasado y apunta al futuro de la patria. La alegoría no contiene elementos republicanos. Hay niños, como futuro de la nación, jugando detrás de la bandera que, lamentablemente, desde esta perspectiva parece más a un saco (figura 4). En la base hay cuatro nichos con cuatro grupos que representan las tres razas formadoras del Brasil y la re- 
ligión católica. La representación se hace a través de referencias a poemas considerados "nacionales": $O$ Caramuru de Santa Rita Durão (referencia a la raza "blanca"), $A$ cachoeira de Paulo Afonso de Castro Alves (raza "negra"), Y-Juca Pirama, el canto vi del poema Os timbiras de Goncalves Dias (raza "amarela”) y finalmente el canto II del poema Anchieta de Fagundes Varella (la religión). En el nicho principal es expuesto un altar cívico, dominado por una mujer que simboliza la fusión de razas, que ofrece una flor como símbolo de la fraternidad humana.

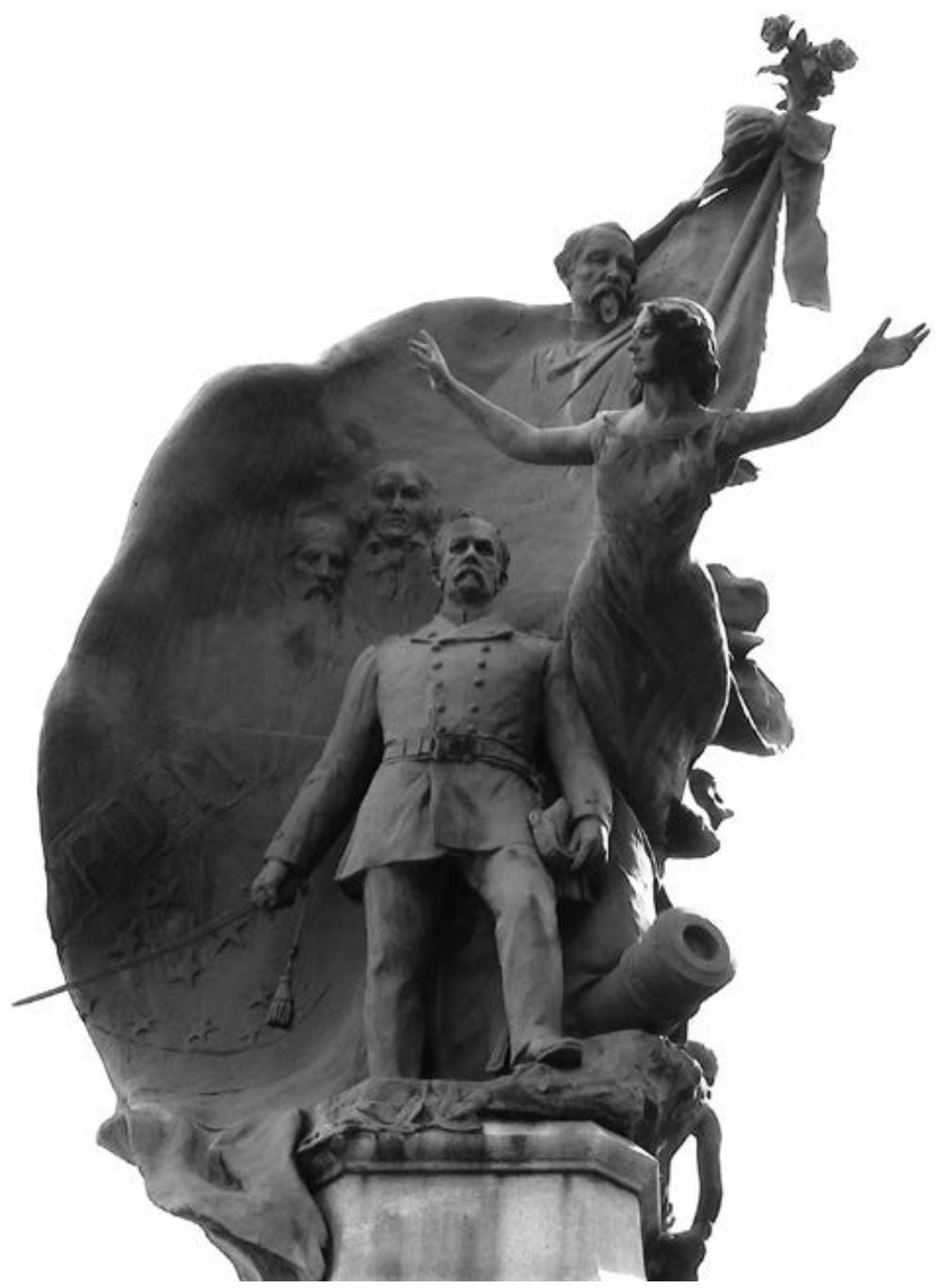

Figura 4. Floriano Peixoto

Fuente: fotografía de Daniela Verztman. 


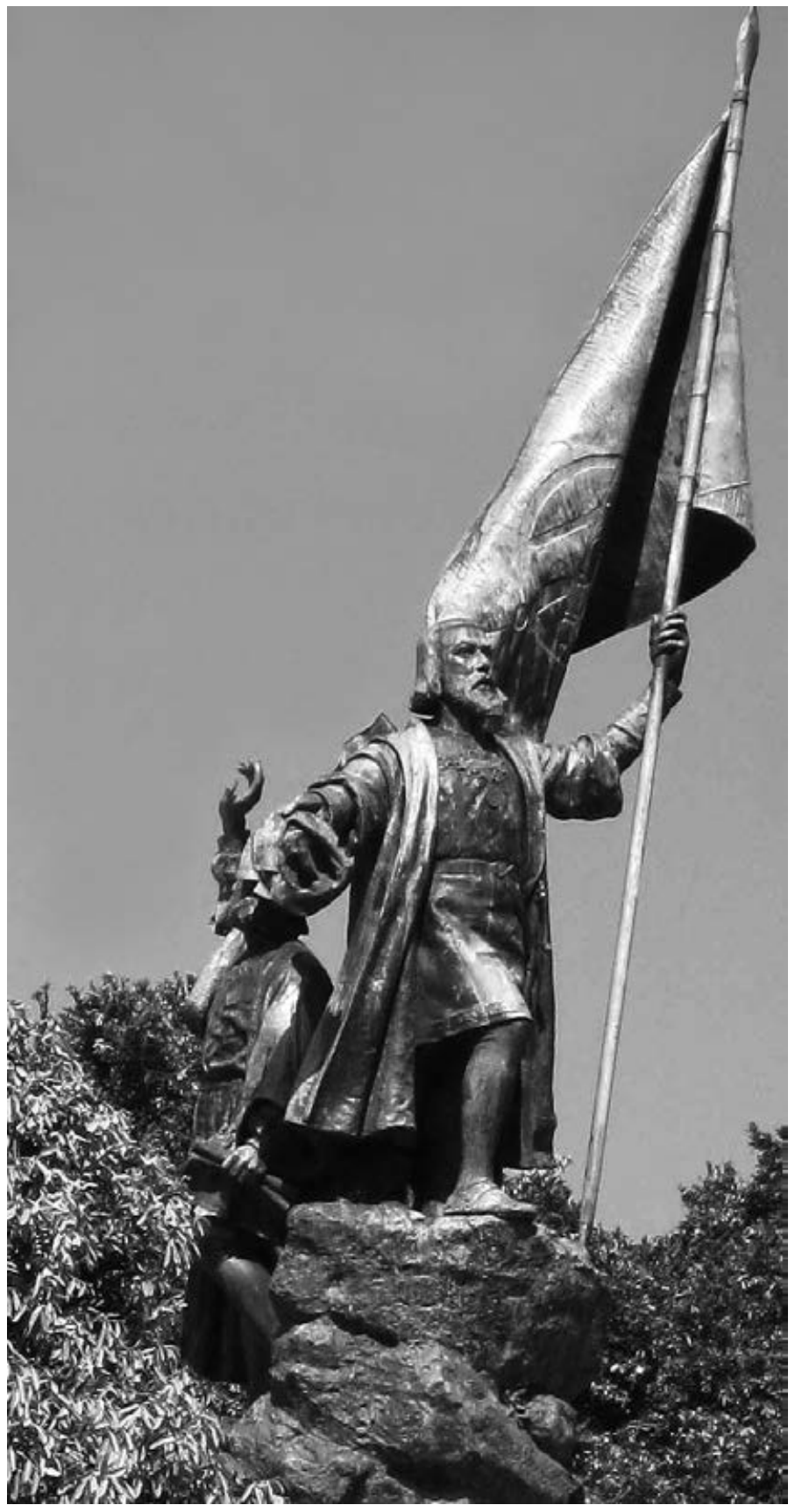

Figura 5. Pedro Álvares Cabral

Fuente: fotografía de Sven Schuster. 
En este monumento podemos ver el fracaso de los florianistas y de los militaresjacobinos frente a los positivistas, o mejor, frente a la iglesia positivista brasileña, cuyo director fue Teixeira Mendes. Los positivistas no fueron activos en la comisión, pero tuvieron influencia discreta en el artista (Leal 2004, 7). Cualquier referencia biográfica a las proezas militares de Floriano es suprimida, así como son disminuidos los elementos bélicos representados (el cañón y la espada). El monumento es puramente alegórico y dominado por los símbolos oriundos de la ortodoxia positivista, con su doctrina de que el arte debería provocar sentimientos armónicos, exaltar el lado altruista y afectivo del ser humano, promover el culto cívico de la familia, patria y humanidad, pero no instigar la revolución o el espíritu militarista. Predominan los trazos de Clotilde de Vaux (la mujer de Auguste Comte y el ídolo de los positivistas ortodoxos), que no representan de forma alguna la república, pero sí la "matria”, según la doctrina positivista imaginada como madre virgen y (por partenogénesis) rodeada de niños. En lugar de armas hay flores, en lugar de motes nacionalistas hay poesías. A Floriano prácticamente no se le aprecia, por la sombra de la bandera que (esa sí) expone el mote positivista "Ordem e progresso", y hay que añadir que el militar odiaba tanto la bandera como el mote (Carvalho 1990, 48). Para completar la subversión, la estatua de Floriano Peixoto mira al sur, lo que provoca el curioso pero lógico efecto que la bandera lo deja casi todo el año poco visible por la sombra — no se sabe si el posicionamiento fue por accidente o intencional-.

El tercer monumento, Cabral, esculpido por Rodolfo Bernardelli e inaugurado en 1900 en el Largo da Glória, representa al “descubridor” de Brasil, Pedro Álvares Cabral (figura 5). Fue proyectado en el contexto del Cuarto Centenario del descubrimiento por la asociación de los festejos. Muestra a Álvares Cabral acompañado por su escribano Pêro Vaz de Caminha y por el Fray Henrique. Simboliza, entonces, los tres agentes civilizadores: las armas, las letras y la cruz. El planeamiento y la recepción de ese monumento, en homenaje a los antepasados, no provocó en su época muchas polémicas (algo que cambió en el 2000).

Todos parecían estar contentos: los republicanos, los monarquistas y los positivistas y el embajador portugués. Lo interesante, empero, es la ceremonia de inauguración. Gonzaga Duque, cronista, crítico de arte y autor del libro didáctico Revoluçôes brasileiras de 1897, escribe en su diario sobre la cena presenciada por él:

Chegamos no momento que os cordões do véu que cobre o monumento são entregues ao Presidente da República e ao Embaixador Português. [...] As duas autorida- 
des puxam os cordões e... nada! sacodem-nos com mais força... Nada! Outra vez sacodem-nos com mais força... Nada! Há um burburinho na multidão. As duas autoridades cruzam os olhares desconfiadamente e esperam que o barão arranje as coisas de modo a não fazerem figuras de ... estica cordas! Mas o barão por sua vez não sabe como se arranjar, o Dr. Frontin anda a cochichar por aqui e por ali, também atrapalhado. Até que enfim surgem dois populares, um branco e um preto, que caminham pelo pedestal. Mas o negro é mais ágil, grimpa-se com facilidade, alcança o ombro de frei Henrique. E ai pára, ou por falta de fôlego ou por temor de ir acima. A multidão bate as palmas, excitando-o com humor e ele já vai pelo Pedr'Álvares. Agarra-se à bandeira do descobridor, aproxima-se do ápice da bandeira, mete mãos ao laço corrediço que acabava de pregar tão grande peça às autoridades, puxa-o, repuxa-o, dá-lhe safanões e... Bravô! Hurrah! gritam todos numa trovoada de aplausos - o véu desaba, ao som dos hinos, estalar de foguetes, guinchos de lanchas, repiques de sinos e salvas de artilharia. Uma inferneira! (Lins 2000, 108)

Comparada con la versión oficial en el Livro do centenário, que documentó todos los festejos, se perciben algunas correcciones significativas:

Foi nesta aflitiva conjuntura que da multidão surgiu um homem. Com espanto de todos ele subiu ao plano em que os representantes dos povos português e brasileiro se colocaram. [...] A atitude do homem era resoluta. Ofereceu-se para subir e, logo que sua proposta foi aceita, começou a galgar o monumento. [...] Chama-se o homem, a quem se deveu a feliz epronta solução deste incidente, Martim Francisco de Paula; foi praça do $7^{\circ}$ batalhão de infantaria é énatural do Ceará. A Associação do Centenário gratificou-o logo com 100\$, dando $20 \$$ a outro homem do povo que o auxiliara. (Lins 2000, 109)

La escena, que se quedó en el imaginario popular, contiene aspectos culturales de negritud que salvan a las autoridades, visiblemente incompetentes, de un apuro. En plena época de la ideología del "blanqueamiento" de la población brasileña, significaba una muestra de apoyo que las autoridades habrían preferido no necesitar. El acto es simbólico, pues hace al "recalcado invadir a cena" (Lins 2000, 6). Por eso los acontecimientos tuvieron que ser neutralizados y sutilmente transformados: ahora privilegian el papel del ayudante secundario, "blanqueando" al héroe y omitiendo al personaje popular más ágil, que es, sin embargo, negro. Lo hacen pedir permiso 
obedientemente a las autoridades (que en verdad no estaban en condiciones de actuar) y además destacan su pasaje por el ejército, lo que lo asocia directamente a la nación, dejando su acto casi como una obligación de servicio (y no un acto cívico).

Podemos resumir los tres ejemplos de la siguiente forma: en el caso de la estatua de Pedro I, la reacción, inesperadamente rígida, contra la narrativa monárquica por parte del poder tuvo como efecto que no se habrían de intentar otras representaciones monárquicas durante casi tres décadas. Se mostró que existen discursos disonantes, críticos contra la interpretación oficial de la independencia, que se alimentan por la figura simbólica, popular y mítica de Tiradentes. Incluso en la República, el episodio continuó siendo problemático y solamente fue controlado a través de la militarización, desviando la mirada hacia la guarda de corps de Pedro I. El feriado del 7 de septiembre, hasta hoy, es dominado por desfiles militares. En el caso del monumento a Floriano Peixoto, se percibe una cautelosa conciliación entre los grupos hegemónicos por parte del artista, pero que fracasó, pues no dejó a ninguno contento. El monumento, con su combinación de discursos incompatibles, fue discutido controversialmente (¿un monumento a la religión de la humanidad? Y ¿ por qué homenajear a Floriano, el "héroe errado”?). Terminó siendo un monumento a la religiáo da humanidade, lo que los florianistas no percibieron a tiempo, lo cual ayudó a los positivistas a engullirse la rana floriana. En el tercer caso, el monumento en homenaje a Álvares Cabral fue exitoso, pero la puesta en escena fracasada y la tentativa de concertar lo ocurrido en el discurso oficial reveló la vulnerabilidad del discurso oficial del blanqueamiento en el cual fácilmente pueden ser detectados los mecanismos de represión de la realidad social. Los tres ejemplos muestran también que la inauguración de monumentos nacionales no era necesariamente un evento que inspirara el sentimiento nacionalista y así contribuyó a forjar los lazos eternos de la patria — podría ser también, como en los casos estudiados, un momento para poner al descubierto la fragilidad de tal sentimiento, la desavenencia de los ciudadanos y, en el peor de los casos, podría ser un momento, largamente memorizado, en el cual se hizo de la figuración nacional un desfiguro-.

\section{Bibliografía}

Achugar, Hugo. 1998. "Parnasos fundacionales, letra, nación y estado en el siglo XIX". En La fundación por lapalabra: Letray nación en América Latina en el sigloXIX, editado por Hugo Achugar, 39-77. Montevideo: Universidad de la República. Agulhon, Maurice. 1988 [1978]. "La statuomanie et l'histoire". En Histoire vagabonde, 137-185. Vol. 1. París: Gallimard. 
Anderson, Benedict. 1991 [1983]. Imagined Communities: Reflections on the Origin and Spread of Nationalism. London \& New York: Verso.

Blanchard, Peter. 2008. Under the Flags of Freedom: Slave Soldiers and the Wars of Independence in Spanish South America. Pittsburgh: University of Pittsburgh Press.

Carvalho, José Murilo de. 1990. A formação das almas: o imaginário da República do Brasil. São Paulo: Companhia das Letras.

D’Alessandro, Sonia. 2003. “Tiradentes: del inconfidente al héroe”. En Derechos de memoria: actas, actos, voces, héroes y fechas: nación e independencia en América Latina, editado por Hugo Achugar, 267-340. Montevideo: Universidad de la República.

Enders, Armelle. 2000. “'O Plutarco brasileiro’: a produção dos vultos nacionais no Segundo Reinado". Estudos Brasileiros 25: 41-62.

Gutiérrez Viñuales, Rodrigo. 2004. Monumento conmemorativo y espacio público en Iberoamérica. Madrid: Cátedra.

Herstal, Stanislaw. 1972. Dom Pedro: estudo iconográfico. 3 vols. São Paulo \& Lisboa: MEC/Casa da Moeda.

Hobsbawm, Eric. 1990. Nation and Nationalism since 1780: Programme, Myth, Reality. Cambridge: Cambridge University Press.

Leal, Elizabete. 2004. "Idéias em bronze: a construção do monumento a Floriano Peixoto". Anais do XVII Encontro Regional de História: O lugar da História (CD rom). Campinas: ANPUH/sP-UNICAMP.

Lins, Vera. 2000. “Imagens que pensam os trópicos”. Revista Locus (UFJF/MG): 101-113. Machado de Assis, Joaquim Maria. 2008. Comentários da semana, editado por Lúcia Granja y Jefferson Cano. Campinas: Unicamp.

Meneses, Ulpiano T. Bezerra de. 2003. "Fontes visuais, cultura visual, história visual: Balanço provisório, propostas cautelares”. Revista Brasileira de História 23, n. ${ }^{\circ}$ 45: 11-36.

Nipperdey, Thomas. 1976 [1968]. "Nationalidee und Nationaldenkmal in Deutschland im 19. Jahrhundert”. En Gesellschaft, Kultur, Theorie: gesammelte Aufsätze zur neueren Geschichte, 133-173. Göttingen: Vandenhoeck \& Ruprecht.

Ozouf, Mona. 1984. “Le Panthéon, l'École Normale des morts”. En Les lieux de mémoire, editado por Pierre Nora, 139-166. Vol. 1 (La République). Paris: Gallimard.

Paladino, Clara. 2003. "Fiesta y contrapunto: miradas en las celebraciones de la independencia en América”. En Derechos de memoria. Actas, actos, voces, héroes y 
fechas: nación eindependencia en América Latina, editado por Hugo Achugar, 123-188. Montevideo: Universidad de la República.

Rausch, Helke. 2006. Kultfigur und Nation: Öffentliche Denkmäler in Paris, Berlin und London 1848-1914. München: R. Oldenbourg.

Tacke, Charlotte. 1995. Denkmal im sozialen Raum: nationale Symbole in Deutschland und Frankreich im 19. Jahrhundert. Göttingen: Vandenhoeck \& Ruprecht.

Wink, Georg. 2009.Die Ideevon Brasilien: Eine kulturwissenschaftliche Untersuchung der Erzählung Brasiliens als vorgestellte Gemeinschaft im Kontrast zu Hispanoamerika. Frankfurt/M.: Peter Lang. 